\title{
Filtering Tort Accidents
}

Jef De Mot, Ben Depoorter and Thomas J. Miceli

\section{ABSTRACT}

Conventional wisdom in the economic analysis of tort law holds that legal errors distort incentives, causing behavior to depart from the optimum. If potential injurers know that courts err, they may engage in less or more than optimal precaution. This article revisits the effect of judicial error on the incentives of potential injurers by identifying a heretofore-neglected filtering effect of uncertainty in settings of imperfect judicial decision-making. We show that when courts make errors in the application of the liability standards, uncertainty about erroneous decision-making filters out the most harmful torts but leaves unaffected less harmful accidents. Our insight applies to various procedural and institutional aspects of legal adjudication, including the randomization of case assignment, the strength of precedent, and the use of standards versus rules.

JEF DE MOT is professor of economics at Hasselt University, Department of Economics and Public Policy. BEN DEPOORTER is Max Radin Distinguished Professor of law and economics at the University of California, Hastings. THOMAS J. MICELI is professor of economics at the Department of Economics University of Connecticut. 


\section{INTRODUCTION}

Legal indeterminacy has a bad reputation in the legal academy. Legal scholars fault legal uncertainty for undermining the rule of law and the legitimacy of the legal system. ${ }^{1}$ Economic scholarship highlights how uncertainty may raise the costs of litigation and erode the deterrent effect of the law. ${ }^{2}$ In the tort context, economic contributions have explained the various ways in which uncertainty distorts incentives to take care (Craswell and Calfee 1986; Shavell 1987), distinguishing across situations where sanctions increase gradually (Kahan 1989) and errors involving the application of rules or standards (Dari-Mattiacci 2005).3 In light of these asserted costs of uncertainty, scholarship is preoccupied with increasing overall predictability in adjudication. 4

In this article we identify a novel, hitherto neglected, benefit of indeterminacy in adjudication. We extend the economic analysis of deterrence by considering the relationship between uncertainty and imperfect judicial decision-making. 5 We show

\footnotetext{
${ }^{1}$ For an overview, see Johnson (1995).

${ }^{2}$ Outside of the tort law context, a few contributions have showed the ways in which uncertainty can have the virtuous effects of moderating issues relating to, for instance, excessive market power (Ayres and Klempeter 2004) and negotiations (Ayres and Talley 1995).

${ }^{3}$ Additionally, a few recent contributions focus on the effect of factual and legal uncertainty on private utility instead of social welfare (Baker and Raskolnikov 2017; Raskolnikov 2017).

4 See, for instance, in patent law, Lemley \& Shapiro (2005). In the broader context of (in)determinacy of enforcement, of course, uncertainty has been pointed out to have desirable attributes, including the deterrent effect on riskaverse offenders. For experimental evidence, see Baker et al. (2003).

5 Note that there are different potential types of legal uncertainty. In this article, legal uncertainty implies that, for a given level of error, individuals do not know whether they will be subject an erroneous judicial decision (i.e. they do not know whether they will face a judge or court that makes an error or not). By contrast, Calfee and Craswell (1986) define a function $F(x)$ which represents the relationship between a defendant's level of care $(x)$ and the probability of a fine (or penalty) being imposed. They interpret the standard deviation of $F(x)$ as a measure of legal uncertainty.
} 
that if tortfeasors cannot predict whether a court will make an error, this uncertainty in tort adjudication 6 has a beneficial "filtering effect" on the frequency and types of accidents that occur in society. ${ }^{7}$ Specifically, we show how uncertainty about the incorrect application of liability standards prevents more harmful accidents while leaving unaffected less harmful accidents.

The observation that, given judicial error, uncertainty may have a beneficial effect on deterrence, is an example of the Theory of Second Best-when there is a distortion (imperfect judicial decision making), adding a second distortion (uncertainty) does not necessarily increase the inefficiency. The intuition can be described as follows. Assume a distribution of judges that includes a fraction of judges that make inefficient decisions involving negligence. Specifically, a fraction of judges excuses injurers even though the costs of prevention to the injurer are lower than the expected accident costs. This may happen because some judges do not apply the efficient tort standards, apply them incorrectly, or simply reject the efficient outcome because of ideological preferences. ${ }^{8}$ Generally, this possibility of a type II error (false acquittal) will result in underdeterrence if injurers know with certainty what type of judge will handle the case. However, if there is uncertainty about the judge, injurers may nevertheless take care because the expected liability cost may still exceed the cost of care. The filtering occurs because uncertainty will be most effective in

${ }^{6}$ Filtering effects are not necessarily confined to a tort setting but could arise in any situation in which precautions can be taken to avoid harm (e.g. also in a contract setting).

${ }^{7}$ Filtering effects have previously been recognized in the context of sharing rules (Dari-Mattiacci and De Geest 2005). Our analysis identifies filtering in the more general setting of uncertainty.

8 This section focuses on type II errors, but the model below will also take into account type I errors. 
deterring those injurers who can avoid an accident at lowest cost-that is, those whose care is most efficient.

A numerical example illustrates the filtering mechanism. Assume that there are three types of risk-neutral injurers, A, B, and $\mathrm{C}$, who engage in a risky activity with the same frequency. Each injurer's activity causes harm of 100 if no precaution is taken, but potential injurers can avoid harm with certainty by taking care. However, the cost varies: for injurer A it costs 30, for injurer $\mathrm{B}$ the cost is 60 , and for injurer $\mathrm{C}$ it is 90 . Thus, if no precaution is taken, the social loss is 70 for activity A, 40 for activity B, and 10 for activity C. Now consider an imperfect court system where judges fall into two categories. The first comprises judges who apply the Hand test correctly in determining the negligence standard, holding injurers liable only if the costs of precaution are less than the level of harm (100). Assume these "efficient judges" constitute $75 \%$ of the population. The remaining $25 \%$ of judges incorrectly excuse injurers as long as their precaution costs exceed 50 (half of the harm).

Observe first that it is socially efficient for all injurers to take care in this example. However, if injurers know with certainty what type of judge they will confront, only type A injurers will take care all of the time, while both type $B$ and $C$ injurers will not take care if they know they will confront an inefficient judge. Expected social losses from these two types of injurers are therefore $(.25)(40)=10$ for type B's, and $(.25)(10)=2.5$ for type C's. Total expected losses across the three types of injurers are therefore $(0+10+2.5) / 3=4.17$.

In reality of course, injurers do not always know with certainty what type of judge they will face or whether a court will apply an efficient rule or apply the rule correctly (for instance in a multijurisdictional setting with diverse rules). If there is uncertainty among injurers about what type of judge they will face, expected liability from failing to take care is $75(=.75 \times 100)$, so both type A and type $B$ injurers will now always take care, but type $C$ will not. 
Total losses in this case are therefore $(0+0+10) / 3=3.33$. Overall losses are therefore reduced when there is uncertainty about judges because of the filtering effect-that is, conditions of uncertainty are more likely to deter more harmful behavior as compared to conditions of certainty.

The filtering effect suggests that certainty about the efficient application of the legal rule is not always an improvement over situations where there is uncertainty. Of course, this finding does not imply that uncertainty is always preferable to certainty. Our model will show that the existence and magnitude of the filtering effect depends on the fraction of inefficient judges and on the severity of the errors by these judges. When the fraction of inefficient judges is relatively large and these judges' errors are relatively small, certainty is more efficient than uncertainty. ${ }^{9}$

The next section provides a formal model of this mechanism, and the following section discusses applications.

\section{The FILTERING EfFECT OF UnCERTAINTY: A Formal MOdeL}

Consider the following simple unilateral care accident model. Let $H$ be the expected harm from an accident, and let $c$ be the cost of care that avoids the accident altogether. ${ }^{10}$ While we assume that $H$ is the same for all accidents, we suppose that injurers vary in their costs of care, and are distributed according to the density function $q(c)$ over the interval $[\mathrm{o}, C]$, with $\mathrm{C}>\mathrm{H}$. For injurers with $\mathrm{c} \leq \mathrm{H}$, it is efficient to take care, but for injurers with $\mathrm{c}>\mathrm{H}$, it is inefficient to do so. In the social optimum, in which the former type of injurers takes care and the latter type does not, total costs would be

9 The model also shows the importance of the distribution of the type of injurers. In our example, if there are sufficiently more injurers of type $\mathrm{C}$ than of type B, the social loss will be lower under certainty.

10 The model in this section involves discrete care choices by injurers. 
$6 /$

$T C^{*}=\int_{0}^{H} c q(c) d c+\int_{H}^{C} H q(c) d c$,

Assume that the assignment of liability is governed by a negligence standard. Thus, when a case comes before a court, the judge must decide whether the injurer should be held responsible for the harm suffered by the victim. ${ }^{11}$ If the rule functioned perfectly, the efficient outcome would be achievedthat is, only those accidents for which the precaution costs of the injurer are larger than the expected harm would actually happen. We assume, however, that the population of judges includes some who apply the Hand test with error. ${ }^{12}$ In particular, some "lenient" judges hold injurers not liable even if their costs of care are less than the harm. In other words, they commit type II errors. At the same time, some other "strict" judges hold injurers liable even if their costs of care outweigh the harm. That is, they commit type I errors. Such departures from efficiency might result from simple computation errors in applying the negligence standard, or from judicial aversion to efficiency as the sole determinant of liability. For example, some judges may have ideological difficulties with the Hand test approach to the negligence rule and either excuse injurers even if their precaution costs are below the harm or hold them liable even if their costs exceed the harm. ${ }^{13}$

We formalize the behavior of judges as follows. A fraction $p^{-}$ are lenient-i.e., they make errors by not holding injurers liable if their precaution costs exceed a given amount $I^{-}<H$, whereas another fraction $p^{+}$are strict-i.e., they hold injurers liable if

${ }^{11}$ We assume for simplicity that the victim himself cannot take any precaution and that all judges know the victim cannot take any precaution.

12 We assume this distribution is exogenously determined. It does not depend on the level of certainty. In reality, the distribution could be endogenous.

13 Some judges may, for instance, find that it would be unfair to oblige a relatively less wealthy injurer to compensate harm that was imposed upon a more affluent victim. Conversely, some judges may believe that strict liability should govern the assignment of responsibility for damages. 
their costs are less than $I^{+}>H$. We assume $I^{+} \leq C$. The remaining judges, comprising a fraction $1-p^{-}-p^{+}$, are efficient and hence do not make errors-i.e., they hold injurers liable if and only if their precaution costs are smaller than the true level of harm. Thus, injurers with $I^{-}<c<H$ wrongly escape liability if facing a judge who is too lenient, while injurers with $H$ $<c<I^{+}$are wrongly held liable if facing a judge who is too strict. Potential injurers must decide how much care to take in light of the likely accuracy of the courts. Assume two worlds with different degrees of uncertainty with regard to the application of the negligence rule. In a world of certainty, injurers know what type of judge they will face when making their care choice, whereas in a world of uncertainty, they do not know what type of judge will handle the case.

Proposition 1: If $\left(1-p^{-}\right) H<I^{-}$, certainty is always preferable.

\section{Proof:}

When potential injurers know the type of judge they will face, injurers who know they will confront a lenient judge will only take care if $c \leq I^{-}$. Thus, injurers with $I^{-}<c \leq H$ will refrain from taking care; this is the inefficiency arising from type 2 errors. ${ }^{14}$ On the other hand, injurers who are aware that they will face either an efficient judge or a strict judge will make the efficient care decision; that is, they will take care if and only if $c$ $\leq H$. This is obvious for efficient judges. It also applies to strict judges because, even though injurers with $H<c \leq I^{+}$will be "wrongly" held liable, it is cheaper for injurers to refrain from taking care and just to pay the damages of $H$. From their perspective, it is as if the applicable rule is strict liability. For this reason, type I errors do not result in inefficient behavior by ${ }^{14}$ Injurers with $c>H$ will also refrain from taking care, but this is efficient. 
injurers. ${ }^{15} 16$ Finally, injurers with $I^{+}<c \leq C$ will efficiently choose to refrain from taking care because they will not be found negligent by any judge. Total costs in this case are

15 The asymmetry between type I and type II errors in our model is a consequence of the assumption that judicial error involves the application of the negligence standard. If instead judges misestimate the amount of damages from an accident, $H$, then both types of errors would produce inefficient choices by injurers. For example, if the true harm equals 100 but some judges believe it is 50, injurers with cost of care between 50 and 100 will inefficiently refrain from taking care (a type II error). In contrast, if some judges believe the harm is 150 , injurers with costs of care between 100 and 150 will inefficiently take care (a type I error). In this context, filtering effects occur not only for type II errors but also for type I errors. Consider this following numerical example that focuses on type I errors. Suppose that 80 percent of judges do not make errors (they believe the harm is 100), but 20 percent of judges believe the harm is 150 . Under uncertainty, an injurer with precaution costs between 100 and 110 will take precaution (if the injurer does not take care, the expected award equals $0.8 \times 100+0.2 \times 150=110)$, but an injurer with precaution costs between 110 and 150 will not.

${ }_{16}$ The filtering effect of uncertainty may also pertain in circumstances where judicial error about the negligence standard may induce over-deterrence. The following example, in which precaution does not entirely eliminate the accident loss, illustrates this. Suppose that an injurer must decide between two alternative precautionary measures (A and B). Prevention measure A costs 50 and is the socially optimal level of precaution. If the injurer selects A, the residual accident costs are 100. Instead, if the injurer selects precaution $\mathrm{B}$, the residual accidents costs are 95 . We distinguish between situations that involve relatively low precaution costs (B costs 60) and consequently relatively low social losses if the injurer takes too much care, on the one hand, and situations involving relatively high precaution costs (B costs 80) and relatively high social losses if the injurer takes too much care, on the other hand. Also, assume that 80 percent of judges take the efficient decision (demanding precaution $\mathrm{A}$ ), and that 20 percent of judges make an inefficient decision (demanding precaution B as long as its cost is lower than e.g. 90). It follows that in the case of certainty, there is a 20 percent chance that due care will be set unambiguously at $\mathrm{B}$. Injurers will engage in precaution $\mathrm{B}$ regardless of whether the cost is 60 or 80 . If they take precaution A, they bear the residual accident costs of 100 , which is a worse outcome for them. In other words, there is no differentiation between the case of high social losses and low social losses under a regime with certainty. Compare this to the outcome under uncertainty. When precaution costs are relatively low (B costs 60), the injurer will take too much care. If he does not engage in excessive care, the injurer's expected costs will be $50+0.2 \times 100=70$. This exceeds the cost of precaution of 60 for B (if he takes B, no judge will find him negligent). When precaution costs are relatively high (B costs 80 ), the injurer will not take too 


$$
T C_{c e r t}=p^{-}\left[\int_{0}^{I^{-}} c q(c) d c+\int_{I^{-}}^{C} H q(c) d c\right]+\left(1-p^{-}\right)\left[\int_{0}^{H} c q(c) d c+\int_{H}^{C} H q(c) d c\right]
$$

The social loss from the inefficient judges in this case is the difference between this expression and (1), or

$$
S L_{c e r t}=T C_{c e r t}-T C^{*}=p^{-}\left[\int_{I^{-}}^{H}(H-c) q(c) d c\right]
$$

This represents the additional accident costs that result in those cases where injurers, knowing they would confront a lenient judge, fail to take care.

Now consider the case where injurers are uncertain about what type of judge they will face, though they know the probabilities of facing each type of judge. If an injurer takes care, his or her costs will be $c$ with certainty because no accident will occur, whereas if he or she does not take care, his or her costs depend on $c$. First, all injurers with $c \leq I^{-}$will be held liable by all judges, so they will all take care. Second, all injurers with $c>$ $H$ will refrain from taking care no matter what judge they expect to face because whether or not they will be held liable, it is cheaper not to spend $c$. Our interest is therefore on injurers with $I^{-}<c \leq H$. These injurers will only be held liable by efficient and strict judges, which will happen with probability $1-p^{-}$. Thus, injurers in this range will take care if $c \leq\left(1-p^{-}\right) H$ and will not take care if the reverse is true. If $\left(1-p^{-}\right) H<I^{-}$, there is no overlap between $I^{-}<c \leq H$ and $c \leq(1-p) H$. Consequently, under uncertainty, injurers with $I^{-}<c \leq H$ never take care. In this case, the social loss is

$$
S L=\int_{I^{-}}^{H}(H-c) q(c) d c
$$

much care. Once again, if the injurer takes optimal precaution A, his expected costs equal $50+0.2 \times 100=70$. This is lower than the injurer's private costs when taking B (80). In conclusion, also in this situation a regime of uncertainty differentiates between situations of low and high social losses. 
$10 /$

which is clearly larger than $S L_{\text {cert }}$. Intuitively, when $\left(1-p^{-}\right) H<I^{-}$ , injurers with precaution costs between $I^{-}$and $H$ never take care under uncertainty, while these injurers still take care under certainty with a positive probability.

Proposition 2: If $\left(1-p^{-}\right) H>I^{-}$: (i) uncertainty has a filtering advantage; (ii) the social loss is more likely to be lower under uncertainty than under certainty as $I^{-}$decreases and as the proportion of injurers with relatively low (high) precaution costs increases (decreases); (iii) the influence of a change in $p^{-}$on the difference in social loss depends on the distribution of precaution costs.

\section{Proof:}

(i) If $\left(1-p^{-}\right) H>I^{-}$, injurers with $c \leq\left(1-p^{-}\right) H$ take care while those with $\left(1-p^{-}\right) H<c \leq C$ do not, resulting in total costs of

$$
T C_{u n c}=\int_{0}^{\left(1-p^{-}\right) H} c q(c) d c+\int_{\left(1-p^{-}\right) H}^{C} H q(c) d c
$$

which produces a social loss of

$$
S L_{u n c}=T C_{u n c}-T C^{*}=\left[\int_{\left(1-p^{-}\right) H}^{H}(H-c) q(c) d c\right]
$$

The care by injurers over the range from $I^{-}$to $\left(1-p^{-}\right) H$ in this case represents what we referred to as the "filtering effect" of uncertainty. It represents the social gain from uncertainty about judge types. The necessary condition for this effect to be present, $\left(1-p^{-}\right) H>I^{-}$, can be rewritten as

$$
p^{-}<1-\frac{I^{-}}{H}
$$

Thus, a filtering effect is more likely if: (a) the fraction of lenient judges (those who commit type 2 errors) is not too large; and (b) the severity of lenient judges' errors, represented by a small value of $\frac{I^{-}}{H}$, is significant. In contrast, when the ratio $\frac{I^{-}}{H}$ approaches 1 , 
then certainty is preferable to uncertainty (see proposition 1). In many cases, expected harm is relatively easy to document or prove, and consequently the ratio will often be close to 1 . However, when harm is difficult to prove and likely to be underestimated, e.g. because of fuzzy evidence or legal standards that exclude important elements of harm from consideration, or when judges are likely to deliberately underestimate harm due to bias, filtering effects are more likely.

(ii) When (7) holds, the social loss is lower under uncertainty than under certainty if

$\int_{\left(1-p^{-}\right) H}^{H}(H-c) q(c) d c<p^{-}\left[\int_{I^{-}}^{H}(H-c) q(c) d c\right]$

This condition is more likely to be fulfilled as:

(a) $I^{-}$(and thus $\frac{I^{-}}{H}$ with $\mathrm{H}$ fixed) decreases: the partial derivative of the left-hand side of the inequality with respect to $I^{-}$is zero, while it is negative for the right-hand side of the inequality $\left(-p^{-}\left(H-I^{-}\right) q\left(I^{-}\right)<0\right)$. In other words, the greater the departure of inefficient judges from the efficient Hand test, the higher is the likelihood that uncertainty will induce more efficient outcomes. The reason is that a decrease in $I^{-} / H$ raises the filtering advantage.

(b) the proportion of injurers with relatively low precaution costs (between $I^{-}$and $\left(1-p^{-}\right) H$ ) increases, and the proportion of injurers with relatively high precaution costs (between $\left(1-p^{-}\right) H$ and $\mathrm{H}$ ) decreases. The explanation is straightforward. Injurers with precaution costs between $I^{-}$and $\left(1-p^{-}\right) H$ take care under uncertainty (the lower bound of the integral on the left-hand side is $\left.\left(1-p^{-}\right) H\right)$, but they only do so with a probability of $1-p^{-}$ under certainty. And injurers with precaution costs between (1$\left.p^{-}\right) H$ and $\mathrm{H}$ do not take care under uncertainty, but they do so with a probability of $1-p^{-}$under certainty. 
$12 /$

(iii) Taking the partial derivative of the social loss under uncertainty with respect to $p^{-}$gives a value of $p^{-} H^{2} q\left(\left(1^{-} p^{-}\right) H\right)$. For the case of certainty, the partial derivative equals $\int_{I^{-}}^{H}(H-$ c) $q(c) d c$.Clearly, the influence of $p^{-}$depends on the distribution $\mathrm{q}(\mathrm{c})$.

We now look at the case of a uniform distribution $(q(c) \equiv 1 / C)$.

Corollary 1: For a uniform distribution, social loss is lower under uncertainty if $p^{-}<\left(1-\frac{I^{-}}{H}\right)^{2}$.

Proof: For a uniform distribution,

$$
S L_{c e r t}=p^{-}\left[\int_{I^{-}}^{H}(H-c) \frac{d c}{H}\right]=\frac{p^{-}}{2 H}\left(H-I^{-}\right)^{2}
$$

and

$$
S L_{u n c}=\left[\int_{\left(1-p^{-}\right) H}^{H}(H-c) \frac{d c}{H}=\frac{\left(p^{-}\right)^{2}}{2 H} H^{2}\right]
$$

The social loss is lower under uncertainty if $S L_{u n c}<S L_{c e r t}$, or if

$$
p^{-}<\left(1-\frac{I^{-}}{H}\right)^{2} \equiv p_{\max }^{-}
$$

Note that this puts a tighter upper bound on $p^{-}$than (7). Condition (10) is more likely to be fulfilled as $p^{-}$decreases. Also note, as discussed above for the general case, that this condition is more likely to be satisfied as $I^{-} / H$ decreases, holding $p^{-}$fixed. Consequently, the filtering effect is strongest when there is a small fraction of judges who make relatively large errors, or who are intensely biased.

As an illustration, Figure 1 graphs the relationship between $p_{\max }^{-}$ and $I^{-} / H$. 


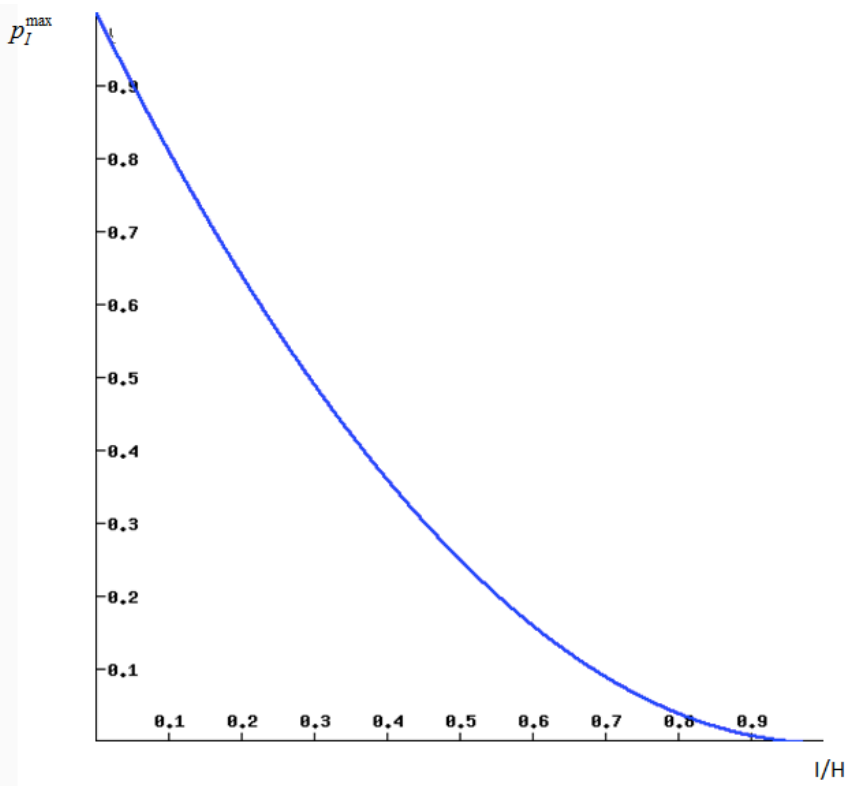

Graph 1. $p_{I^{-}}^{-\max }$ for different values of $I^{-} / H$.

Corollary 2: For a uniform distribution, if the variance of $I^{-}$increases (holding the expected value constant), the desirability of uncertainty increases.

Proof: The reason can be observed in (8) and (9). Specifically, the convexity of (8) in $I^{-}$implies that increasing the variance (risk) of $I^{-}$, while holding its expected value constant, will cause the value of $S L_{c e r t}$ to rise. In contrast, $S L_{u n c}$ is not affected by the variance of $I^{-}$among lenient judges, but only depends on $p^{-}$, the total fraction of those judges. It follows that the social loss in a system of predictable judges increases because more injurers with relatively low precaution costs are not incentivized to avoid accidents-in other words, the filtering advantage of uncertainty increases. 
An increase in the variance of $I^{-}$could for example reflect greater variation in judicial ideology. To illustrate the effect of this increase in variance, we compare an example where 25 percent of judges set a threshold for liability at 50, to one where 12.5 percent of judges set a threshold of 25 and 12.5 percent set a threshold of $75 \cdot{ }^{17}$ The "average ideology" therefore remains the same but the variance has increased. As illustrated by Graph 1, the social loss in the case of a single type of lenient judge is the same under certainty and uncertainty, and equals $3.125 .^{18}$ However, we can show that the example with greater judicial variance causes the loss under certainty to increase, while having no effect on the loss under uncertainty. Consequently, greater judicial variance increases the desirability of uncertainty.

To see this, we first compute the loss under certainty using (8), where $I_{1}^{-}=25, I_{2}^{-}=75$ and $p_{1}^{-}$and $p_{2}^{-}=0.125$, such that $p_{1}^{-} I_{1}^{-}+p_{2}^{-} I_{2}^{-}=50$. The result is $3.91>3.125$. As for the loss under uncertainty, it turns out to be unaffected by the increase in judicial variance. First, injurers with costs less than 25 will all take care. Second, injurers in the range $25<c<75$ will expect to be held liable with probability .825 , making their expected liability from failing to take care 82.5 , so all of these injurers will also take care. Finally, injurers with $c>75$ will expect to be held liable with probability .75 and so face liability of 75 . Thus, none of them will take care. But this is exactly the outcome in the example with a single type of inefficient judge. The filtering disadvantage thus remains the same because what matters is the total number of "lenient judges," which is unchanged. Only the variance increases. Thus, the social loss under uncertainty remains 3.125 in this example, which is lower than the losses under certainty.

${ }^{17}$ All other judges set a threshold of 100.

${ }^{18}$ We obtain this outcome by inserting $p^{-}=0.25$ and $\mathrm{I}^{-}=50$ in either (8) or (9). 
As a final note, it is worthwhile to point out an interesting link between focusing law enforcement and the level of certainty/uncertainty as it affects the filtering effect described in this article. Lando and Shavell (2004) develop the insight that there may exist an intrinsic advantage from focusing law enforcement effort on a subgroup of possible violators of law, rather than enforcing uniformly across the relevant population of potential violators. For example, they discuss the case in which it may be desirable for tax examiners to undertake more audits of individuals whose names begin with the letters A-M than of individuals whose names begin with N-Z. This may be desirable even though the likelihood of tax violations is the same across the two groups. Intuitively, it may be the case that the gain in deterrence in the group for which enforcement effort is focused outweighs the loss in deterrence in the group for which enforcement effort is lowered. To illustrate, Lando and Shavell provide a numerical example in which each individual who files a tax return will obtain a benefit of $\$ 100$ if he falsely claims a deduction and the penalty for making a false claim is $\$ 1,000$. If tax examiners audit all individuals uniformly, the audit rate will be $6 \%$. Consequently, given that the expected penalty will be only $\$ 60$, all (risk-neutral) individuals will make false claims. The auditing will be ineffective. If, however, tax authorities announce that they will use their staff to audit half of the individuals (e.g. those whose names begin with A-M) with probability $12 \%$, these individuals will be deterred from making false claims because of the expected penalty of $\$ 120$. For half of the population, deterrence will rise from none to perfect. For the other half, the probability of an audit will decrease from $6 \%$ to $0 \%$. However, deterrence will be unaffected (it remains at level zero). Hence, in this example, focusing law enforcement efforts on half of the population raises deterrence overall and is desirable.

We can illustrate the effect of filtering in the context of this example by changing two aspects. First, if tax examiners audit all 
$16 /$

individuals uniformly, the audit rate is $50 \%$. If they use their staff to audit half of the individuals, one half will face a probability of an audit of $100 \%$, and the other half faces an audit probability of o \%. Second, suppose that the benefit of falsely claiming a deduction is not fixed at 100, but is uniformly distributed on the interval $(0,100)$ for the entire population. As a result, the situation without focusing is similar to a situation with uncertainty, and only individuals with relatively large benefits (>50) will decide to falsely claim a deduction. The situation with focusing is one of certainty. Both groups know with certainty whether they will be audited or not. Individuals who know they will be audited all refrain from falsely claiming a deduction. Individuals who know they will not be audited will falsely claim a deduction, even if their benefit is very small. Thus, in this example, it may be preferable not to focus law enforcement. However, if most individuals would have a relatively small benefit of falsely claiming a deduction, focusing would be the preferred option.

\section{FILTERING IN CONTEXT: APPLICATIONS}

Although uncertainty is an inherent element of adjudication, institutional and procedural measures have a profound effect on the level of uncertainty in legal systems. In this section, we discuss three examples (randomization of adjudication, the strength of legal precedents, and the choice between rules and standards) in light of the filtering effect.

\subsection{Randomization in Adjudication}

Legal systems infuse uncertainty in adjudication by instituting randomization in adjudication. For instance, some circuits and states randomize the assignment of cases within courts. Randomization of case assignments is a key part of the case assignment procedure in many federal district courts, in the 
federal courts of appeal, in many state trial courts and appellate courts, in federal immigration courts, and elsewhere. ${ }^{19}$ Of course, case assignment would be irrelevant to outcomes if all judges decided cases in an identical manner. As a factual matter, however, adjudicators vary in competence (the ability to achieve preferred goals) and ideology (the goals that are preferred by the adjudicator).20 Consequently, case assignment lotteries randomize the likely decisions and case outcomes in specific cases.

To illustrate the filtering effect of randomization, consider the following numerical example involving case assignments. Assume that some adjudicators are more competent than others. The degree of randomness created by case assignment procedures may differ significantly. Randomness is complete when all cases are assigned by a lottery and all judges are in the same pool. Randomness is less than complete when the caseload is divided, say, into two parts such that the first caseload is assigned by lottery to the pool with the most competent judges, and the second caseload is assigned by lottery to the pool with the least competent judges. Assume further that injurers know ex-ante the pool of judges that they will be assigned to. ${ }^{21}$ Suppose $30 \%$ of judges are relatively inefficient: they excuse injurers if the precaution costs exceed 50 . The remaining $70 \%$ of judges are more efficient: they only excuse injurers if the precaution costs exceed 75 . If randomness in case assignment is complete, all

19 For an example of randomization in case assignment, see the local rules of the Southern District of New York state: "All cases shall be randomly assigned by the clerk or his designee in public view in one of the clerk's offices in such a manner that each judge shall receive as nearly as possible the same number of cases" (S.\&E.D.N.Y.R.50.2(b)(2009)). Lotteries in case assignment affect perhaps millions of cases per year. See Samaha 2009.

${ }^{20}$ Cf. Posner 2008.

${ }^{21}$ Ex ante here is the moment when potential injurers decide how much care to take. This could be the case when each pool of judges deals with different types of cases (e.g. one group exclusively deals with commercial cases). 
$18 /$

accidents with precaution costs lower than 70 will be avoided, but the rest will not be avoided. ${ }^{22}$

Suppose further that the caseload is equally divided across all judges. 23 That means that $30 \%$ of cases are assigned to the more lenient judges, and 70\% to the more efficient judges. In the first group of cases, accidents with precaution costs lower than 50 are avoided but the rest are not. In the second group, accidents with precaution costs lower than 75 are avoided, but the others are not. As this example illustrates, randomization of case assignment may increase uncertainty in a benevolent manner by capitalizing on the differences between efficient and inefficient decision-makers inside courts.

\subsection{The Strength of Precedent}

Legal systems generally differ with regard to the strength of precedent. In a strong precedent system, such as that applicable to U.S. Supreme Court decisions, judges are legally bound by prior judicial decisions. In a weak system of precedent, such as those found in many civil law jurisdictions, prior decisions provide valuable guidance but are not formally binding upon subsequent decision-makers. ${ }^{24}$

The existing literature has revealed several benefits and costs of strong and weak precedent systems (Landes \& Posner, 1976;

${ }^{22}$ We assume a weak system of precedent.

${ }^{23}$ This assumption is not necessary for our results, aligns with the goal of case assignment rules to allocate an even caseload across judges.

24 Although the strictness of precedents is often noted as a major procedural difference between civil and common law jurisdictions, most legal systems are mixed systems of precedent. Theoretically, a line is drawn between the doctrine of stare decisis, which prescribes that courts adhere to past legal precedent on issues of law when deciding pending cases and the doctrine of jurisprudence constante, which hold that judges are bound only when a consolidated trend of decisions has already been established. Judicial decisions do not become a source of law until they mature into a prevailing line of precedents (Dainow 1974 and Dennis 1993). 
Macey, 1998).25 This article adds a novel insight to the debate over the optimal strength of precedent. For litigants, the strength of precedent impacts the level of uncertainty in adjudication. A weak precedent system allows for greater levels of uncertainty. Contradicting rules may emerge from different cases, and potential injurers will select their care level by taking this mixed case law, with efficient and inefficient precedents standing side by side, into account. In a strong system of precedent, by contrast, the existence of an established precedent reduces (but of course does not fully eliminate) the level of uncertainty as to the case outcome. ${ }^{26}$ Once a precedent is set, potential injurers select their level of care on the basis of that precedent, regardless of whether it is efficient or inefficient.

Consider for instance a setting where two alternative legal doctrines might apply to the behavior of a given type of agent with respect to her principal. Each doctrine imposes a different duty of care, e.g. gross negligence versus ordinary negligence. ${ }^{27}$ Suppose that the ordinary negligence duty is efficient. Under a strong precedent system, either the efficient doctrine (ordinary negligence) or the inefficient one (gross negligence) will become precedent. From there on, the agent is certain of the imposed duty of care. Under a weak precedent system, in contrast, both doctrines may co-exist. The agent will be uncertain as to which doctrine will be applied to her conduct in a given situation, and hence to what level of duty she will be held.

Applying the analysis of the previous section, if judicial decision-making is imperfect, the uncertainty created by a weaker system of precedent benefits from the filtering effect described in the previous section. As a result, a weak precedent

25 For an overview of the literature to date, see Depoorter \& Rubin (2017).

${ }^{26}$ A strict precedent system reduces the range of uncertainty by ascertaining the applicable determining rule, but of course does not affect the remaining uncertainty with regard to the application of the particular rule to the specific facts of the dispute.

${ }_{27}$ Of course, we could add other duties of care, e.g. a high trustee standard. 
$20 /$

system may have an efficiency advantage over stronger forms of precedent when the filtering advantage (higher deterrence of very harmful behavior) is higher than the filtering disadvantage (lower levels of deterrence of less harmful behavior) and other costs associated with weak precedents.

\subsection{Rules versus Standards}

Courts or legislators also influence the degree of uncertainty whenever they adopt a new legal rule and must decide how they will formulate legal commands. When legislators and courts institute open-ended standards they increase the amount of decision-making at the judicial level as well as the range of possible outcomes and, consequently, the overall uncertainty. By contrast, when legislators and courts enunciate precise rules that enable mechanical decisions by judges, the overall degree of indeterminacy is likely to be narrower.

Economic analysis treats the choice between rules and standards primarily as a trade-off between the ex-ante costs of norm specification and the costs of ex-post adjudication and administration (Schäfer 2006; Schwartz \& Scott 1995). While open standards require more ex-post interpretation of the law by adjudicators, they offer additional flexibility to tailor outcomes to the specific context of the dispute (Erlich and Posner 1974).

Our insight may add another dimension to the analysis of rules and standards. Specifically, our analysis suggests that the uncertainty associated with open-ended standards could possibly filter out more socially wasteful conduct. By contrast, in reducing the breadth of interpretative opportunities, precise rules reduce the degree of uncertainty while, in the process, forsaking the potential filtering of more socially wasteful conduct.

Since there is no horizontal stare decisis, open standards at the federal level create the potential for circuit splits where 
efficient and inefficient precedents can exist across states. Whenever the U.S. Supreme Court adopts open standards instead of bright line rules, it could in effect be enabling filtering effects for activities of defendants if, as a result, potential injurers cannot predict ex-ante what circuit they will be brought into.

\section{CONCLUSION}

Legal institutions and rules may differ to the extent that they introduce uncertainty in adjudication. Although reducing overall levels of indeterminacy in adjudication is an important goal of procedural reform, this article has suggested that adjudicative uncertainty can also have surprising virtues.

Our analysis reveals how the presence of uncertainty impacts deterrence and, consequently, the occurrence of different types of accidents. When accounting for imperfect decision-making by courts, higher degrees of indeterminacy have a filtering effect: uncertainty prevents the most socially harmful behavior and lets less harmful behavior pass. By contrast, when there is relative certainty with regard to adjudication, there is no filtering of accidents across different levels of harm. We further demonstrated that filtering socially harmful accidents is more valuable when error rates and ideological variance among judges are high.

Our hypothesis could be relevant to many issues of institutional design. For instance, our analysis identifies some insights that could be pertinent to randomizing adjudication, the strength of precedent, and the use of legal rules versus standards. 


\section{BIBLIOGRAPHY}

Baker Scott and Raskolnikov Alex. 2017. Harmful, Harmless, and Beneficial Uncertainty in Law. Journal of Legal Studies. 46: 281-307.

Baker, Tom, Harel, Alon and Kugler, Tamar. 2004. The Virtues of Uncertainty in Law: An Experimental Approach. Iowa Law Review. 89: 443-487.

Craswell, Richard, and Calfee John. 1986. Deterrence and Uncertain Legal Standards. Journal of Law, Economics, and Organization 2:279-303.

Dainow, J. (Ed.) 1974, The Role of Judicial Decisions and Doctrine in Civil Law and in Mixed Jurisdictions. Louisiana State University Press: Baton Rouge, LA.

Dari-Mattiacci, Giuseppe. and De Geest, Gerrit. 2005. The Filtering Effects of Sharing Rules. Journal of Legal Studies 34(1): 207-237.

Dari-Mattiacci, Giuseppe. 2005. Errors and the Functioning of Tort Liability. Supreme Court Economic Review13:165-87.

Dennis, James L. 1993. Interpretation and Application of the Civil Code and the Evaluation of Judicial Precedent, Louisiana Law Review 54: 1.

Depoorter, Ben. 2009. Technology and Uncertainty: The Shaping Effect on Copyright Law. University of Pennsylvania Law Review 157:1831.

Depoorter, Ben, and Rubin, Paul H. 2017. Jude-Made Law and the Common Law Process, in Parisi, F. (Ed.), The Oxford Handbook of Law \& Economics. Oxford: Oxford University Press 129-142.

Ehrlich, Isaac and Posner, Richard A. 1974. An Economic Analysis of Legal Rulemaking. Journal of Legal Studies 3(1): 257-286.

Johnston, Jason Scott. 1991. Uncertainty Chaos and the Torts Process: An Economic Analysis of Legal Form. Cornell Law Review 76: 341-400.

Kahan, Marcel. 1989. Causation and Incentives to Take Care under the Negligence Rule. Journal of Legal Studies 8:42747 . 
Kaplow, Louis. 1992. Rules Versus Standards: An Economic Analysis, Duke Law Journal 42:557-629.

Lambert, Edouard and Wasserman, Max J. 1929. The Case Method In Canada And The Possibilities Of Its Adaptation To The Civil Law. Yale Law Journal 39.

Landes, William, and Posner, Richard A. 1976. Legal Precedent: A Theoretical and Empirical Analysis. Journal of Law and Economics 19 (September): 249-307.

Lando, Henrik \& Shavell, Steven M. 2004. The Advantage of Focusing Law Enforcement Effort. International Review of Law \& Economics 24 :209-221.

Lemley, Mark, A., and Shapiro, Carl. 2005. Probabilistic Patents. Journal of Economic Perspectives 19(2): 75-98.

Macey, Jonathan R. 1989. The Internal and External Costs and Benefits of Stare Decisis. Chicago-Kent Law Review 65 (1): 93-113.

Macey, Jonathan R.. 1998. Precedent, in Newman, P. (ed.), The New Palgrave Dictionary of Economics and the Law, London: Macmillan 69-74.

Posner, Eric A. 2008. Does Political Bias in the Judiciary Matter? Implications of Judicial Bias Studies for Legal and Constitutional Reform, University of Chicago Law Review 75:853-877.

Raskolnikov, Alex. 2017. Probabilistic Compliance. Yale Journal on Regulation 34:491-544.

Samaha, Adam. 2009. Randomization in Adjudication. William and Mary Law Review 51:1-85.

Schäfer, Hans-Bernd. 2006. Rules Versus Standards in Rich and Poor Countries: Precise Legal Norms as Substitutes for Human Capital in Low-Income Countries. Supreme Court Economic Review 14: 113-34.

Schlag, Pierre J. 1985. Rules and Standards, UCLA Law Review 33: 379.

Schwartz, Alan and Scott, Robert E. 1995. The Political Economy of Private Legislatures. University of Pennsylvania Law Review 143: 595-645.

Shapiro, Martin. 1972. Toward a Theory of Stare Decisis. Journal of Legal Studies 1 (1): 125-34. 
$24 /$

Shavell, Steven. 1987. Economic Analysis of Accident Law. Cambridge, MA: Harvard University Press.

Spier, Kathryn. 2007. Litigation. Polinsky A. M. and Shavell, S. eds., The Handbook of Law and Economics, Amsterdam: North Holland 259-342. 